
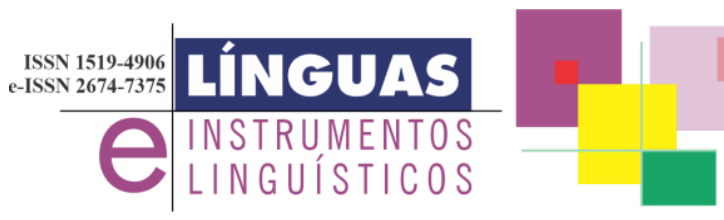

DOI: $10.20396 /$ lil.v24i48.8666083

\title{
O clima da época em torno do conceito de discurso na gramática de Port-Royal: o "bom uso" da língua
}

\section{The zeintgeist around the concept of discourse in Port- Royal gramar: the "good use" of language}

\section{Roberta Soares Paiva* \\ UFPB}

Resumo: Este artigo pretende traçar o clima da época para o conceito de discurso na Gramática de Port-Royal (GPR) quanto ao que se pensava no século XVII sobre o "bom uso" da língua, delimitando a relevância desse texto fundador (COLOMBAT; FOURNIER; PUECH, 2010) no panorama da História das Ideias sobre a Linguagem. Publicada em 1660, a GPR tornou-se famosa por ser considerada um trabalho pioneiro na área da Filosofia da Linguagem. Seus autores pretendiam propor um estudo filosófico e racional da linguagem. A GPR contrastava com a tônica dos estudos linguísticos da época, sintonizados com a preocupação acerca da questão do "bom uso" (bon usage) da língua, compreendido meramente em termos estilísticos. Tal recorte se mostrou necessário devido à generalidade com a qual se investia o conceito de discurso, visto como sinônimo de fala/uso, que deve ser regulado por regras, e influenciou o referencial teórico da Gramática Gerativo-Transformacional de Noam Chomsky.

Palavras-chave: História das Ideias Linguísticas, Gramática de PortRoyal, Discurso, Política linguística.

Abstract: This article intends to trace the climate of time for the concept of discourse in Port-Royal Grammar (PRG) as to what was thought in 
the 17th century about the "good use" of language, which delimitates this founding text's relevance (COLOMBAT; FOURNIER; PUECH, 2010) for the History of Ideas on Language. Published in 1660, PRG became famous for being considered a pioneering work in the area of Philosophy of Language. Its authors intended to propose a philosophical and rational study of language. PRG contrasted with the tone of linguistic studies of the time, which was in tune with the concern about the "good use" of language, understood merely in stylistic terms. Such an epistemological cut was necessary due to the generality with which the concept of discourse was invested, seen as a synonym for speech/use, which must be regulated by rules. This perspective has influenced Noam Chomsky's Generative-Transformational Grammar theoretical construct.

Keywords: History of Linguistic Ideas, Port-Royal Grammar, Discourse, Language policy.

\section{Introdução}

Nesta introdução, serão abordados três momentos que, assim como o continuum da História, interpenetram-se: buscar-se-á delimitar a relevância da Gramática de Port-Royal (doravante GPR) no panorama da História das Ideias sobre a Linguagem, além de elucidar o objetivo deste artigo. Para tanto, o contexto histórico da obra será situado brevemente, como forma de embasar a importância da GPR para a construção de um pensamento linguístico cujo fôlego garantiu o seu lugar na ciência linguística.

A Gramática de Port-Royal, ou Gramática Geral e Razoada (Grammaire générale et raisonnée contenant les fondemens de l'art de parler, expliqués d'une manière claire et naturelle, i.e., Gramática geral e razoada contendo os fundamentos da arte de falar, explicados de modo claro e natural), de autoria dos monges jansenistas Antoine Arnauld e Claude Lancelot, foi publicada na França em 1660. Tornou-se famosa por ser considerada um trabalho pioneiro na área da Filosofia da Linguagem, um texto fundador, de acordo com Colombat, Fournier e Puech (2010). 
O foco da obra recai sobre as regularidades do uso da língua, trazendo um conceito de gramática como um compêndio de regras norteadoras do uso, as quais resultam, por sua vez, de processos mentais universais. Esta ideia, quatro séculos mais tarde, influenciaria sobremaneira a Gramática Gerativo-Transformacional de Noam Chomsky.

Arnauld e Lancelot pretendiam, através da GPR, propor um estudo filosófico e racional da linguagem. O caráter pioneiro da obra se explica pela opção epistemológica de não se prender às línguas clássicas, especificamente ao latim e ao grego, como mirantes para o entendimento das questões da língua vernácula - no caso, o francês - e de outras línguas. Ao contrário, os messieurs de Port-Royal se debruçaram sobre o francês, língua na qual é engendrada a maioria dos exemplos. Assim, os autores pretendiam aliar a pedagogia do ensino de línguas a noções de lógica passíveis de ser aplicadas a uma gramática geral (MOLINA, 2014).

Para o leitor contemporâneo apreciar uma obra de quase 400 anos, é preciso se desnudar de seu olhar, pós-moderno, sincrônico, para imergir no clima na época, i.e., no zeitgeist, na condição sociocultural que caracteriza a constituição das ideias daquela determinada época, num exercício consciente de retrospecção (LAGORIO, 2007).

Vale ressaltar que, na França, a GPR contrastava com a tônica dos estudos linguísticos produzidos na época, sintonizados com a preocupação típica do século XVII com o "bom uso" (bon usage) da língua, compreendido meramente em termos estilísticos e atravessado pela noção do bel usage, ou uso linguístico de orientação preciosista. Para os gramáticos de Port-Royal, conforme já demarcado no prefácio da obra, para apreender a perfeição da palavra, urge não apenas considerar seu uso, mas "[...] conhecer-lhe as razões e fazer cientificamente o que os outros fazem apenas por costume" (ARNAULD; LANCELOT, [1660] 1992, prefácio). Isto revela a preocupação da GPR com o caráter racional do uso, do qual necessariamente careceria uma abordagem centrada no bom uso per se, concebido enquanto o uso correto ou o belo uso da linguagem.

Inserindo-se no mérito dessa discussão, o presente artigo tem por objetivo traçar o clima da época para o conceito de discurso com relação à Gramática de Port-Royal, especificamente no tocante ao que se pensava no século XVII sobre o "bom uso" da língua. Esse recorte se 
mostrou necessário em virtude da generalidade com a qual então se investia o conceito de discurso, visto como sinônimo de fala/uso, a ser regulado por regras. Dessa forma, faz-se necessário resgatar o clima da época em torno do que se prensava sobre o "bom uso" da língua na GPR, posto que a obra discorda do consenso dos gramáticos franceses do século XVII acerca da questão.

\section{Marco Teórico}

Para Santos (2014), Lancelot tinha uma experiência anterior com gramáticas ${ }^{1}$ pedagógicas de várias línguas, o que o teria motivado a ingressar em um novo projeto, que ficou conhecido como Gramática de Port-Royal. Para desempenhá-lo, contou com a colaboração de Arnauld, que embora não fosse um gramático, tinha forte interesse em Filosofia, em especial pelo domínio da lógica, o que lhe despertou o interesse em refletir sobre "[...] os verdadeiros fundamentos da arte de falar" (ARNAULD; LANCELOT, [1660] 1992, prefácio). A lógica, tida como a "arte de pensar", pretendia ordenar o caos da língua comum. Nesse panorama, a gramática se une à lógica para fomentar o desenvolvimento da escrita.

A concepção de língua da obra é a de espelho do pensamento, denotando a língua como expressão de uma razão universal. A GPR enfatiza a morfologia, porquanto, na França setecentista, em franco processo de gramatização (AUROUX, 2009), o que caracterizava as línguas eram as questões formais, os traços morfológicos. Portanto, era crucial erigir uma estrutura conceptual da língua como sistema (langue) que permita a conceptualização, a generalização e a formação de regras.

De acordo com Auroux (2009), define-se uma língua gramaticalizada como sendo uma língua que dispõe de referências e normas. A universalização opera como uma forma de redução da língua a regras comuns a todas as línguas naturais, estratégia importante para "controlar o caos" das então chamadas línguas usuais, conforme denominavam Arnauld e Lancelot com relação às línguas vivas e imersas na dinâmica histórico-cultural, em oposição às línguas clássicas, como o latim, o grego e o hebraico. No afã de controlar a língua para fortalecer o Estado, surgem as Academias e os instrumentos linguísticos, dentre os quais, as gramáticas. 
Para Santos (2014), data de 1635 a criação da Academia da Língua Francesa, por iniciativa do cardeal Richelieu. Isto ocorre em um momento crucial da história da França, em que a elite passava a fazer uso do francês para exercer funções antes reservadas ao latim, processo que se verificava em toda a Europa com relação às línguas vernáculas. Até então, o latim e o grego, principalmente o primeiro, era o parâmetro do uso linguístico, mas agora, com a constituição dos estados nacionais, era uma exigência que se constituíssem protocolos a serem utilizados pelos sujeitos para nortear a sua atividade linguística. Nesse contexto, a Academia da Língua Francesa foi criada como parte do projeto de fortalecimento da unidade e da ordem do Estado francês através da legislação da língua.

A obra se divide em duas partes: a primeira aborda os signos orais ou escritos que transmitem o pensamento, enquanto a segunda se atém à significação desses signos, com vistas a observar como os homens se valiam deles para expressar seus pensamentos. Trata-se de uma Gramática Geral, as quais, segundo Vieira (2018), foram produzidas na esteira de renovação pedagógica e ideológica do Iluminismo e tinham como objetivo promover a articulação entre língua e razão por meio da delimitação dos princípios gerais ou universais e dos princípios particulares de cada língua.

A elaboração de uma Gramática Geral pode atender a duas metodologias: submeter todas as formas de todas as línguas às mesmas categorias, de modo que estas são preexistentes, e não criadas, existindo como um dado da natureza; ou submeter todas as línguas aos parâmetros de uma língua mais antiga, concebida como um reservatório de categorias (AUROUX, 2009). A Gramática de Port-Royal assentase na primeira metodologia.

O viés filosófico de Port-Royal influenciou um estudo da língua de base racionalista, tendo predominado na Europa e especialmente na França durante todo o século XVII. Um dos motivos de a GPR ser considerada um texto fundador é o fato de que ela não se limitou a investigar o que representavam os enunciados somente no nível frasal, mas foi além, ao vislumbrar o que mais tarde seria considerado discurso. Prova disto é que os conceitos de estrutura profunda e estrutura de superfície de Noam Chomsky tomaram por base as ideias de Arnauld e Lancelot. 
Os messieurs de Port-Royal propuseram uma gramática que se situava enquanto proposta de ensino, voltando-se para usos que os falantes faziam da língua. O próprio subtítulo da obra demonstra esse interesse: Contendo os fundamentos da arte de falar, explicados de modo claro e natural; as razões daquilo que é comum a todas as línguas e das principais diferenças ali encontradas etc. Nessa senda, pode-se afirmar que Arnauld e Lancelot estavam preocupados majoritariamente com o modo como as palavras significam, numa orientação epistemológica completamente diferente daquela empreendida na época, cujo interesse linguístico se prendia a aspectos estilísticos. A GPR, portanto, abriu-se para um outro modo de descrever os usos de uma língua.

O processo de nomeação na GPR equivale a um processo de determinação que se manifesta em virtude do que os autores chamam de necessidade de substância. Sendo assim, o usuário da língua, ao se dedicar à atividade de nomear, põe em movimento o mundo das essências. Para Arnauld e Lancelot ([1660] 1992, p. 42), “[...] as palavras são muitas vezes consideradas nas diversas relações que mantêm umas com as outras [...]. Entre essas relações, existem oposições, e isso às vezes acarreta equívocos".

Pode-se depreender desse posicionamento um dos atributos da língua enquanto discurso (língua em uso) que ainda permanece válida nos dias atuais: a tutela da palavra pertence ao sujeito, ao usuário da língua, que produz significados no uso que faz daquela, ou seja, da palavra. Com isso, os autores reconhecem que a língua está em constante e dinâmico processo de ressignificação. Há significados já esperados pelos falantes e há também acidentes, conforme denominam os autores, donde se pode inferir que nem sempre a língua se comporta conforme preconizam as regras formuladas para regular o seu funcionamento, fato mencionado textualmente na primeira parte da GPR. A língua é, portanto, portadora de substâncias. Há um sujeito que opera na materialidade linguística.

\section{Apontamentos de análise}

Nesta seção, pretende-se investigar o conceito de discurso inserido no clima da época que pode ser inferido na obra em estudo, com enfoque para o que se entendia por "bom uso" da língua quando de sua 
produção, considerando que a Gramática de Port-Royal discordava do conceito de bom uso da língua defendido em obras a ela contemporâneas, as quais enfatizavam o aspecto estilístico, sem dedicar maior atenção à investigação das causas, da estrutura e dos fundamentos da linguagem.

A Gramática de Port-Royal surge a partir de uma preocupação quase obsessiva com a expressão clara, conduzindo o gramático a procurar na língua meios adequados para a consideração da lógica do pensamento em detrimento de manifestações que não se afinassem com esse ideal, as quais eram tidas como abusos. Assim, a GPR se sintoniza com o princípio da época segundo o qual a linguagem era regida por princípios gerais e racionais, o que requeria dos falantes a observação de clareza e precisão no tocante ao uso da linguagem. Com o intuito de demonstrar que o sistema ${ }^{2}$ linguístico é proveniente da razão, a obra parte do princípio de que, em prol da clareza das ideias, estas deveriam ser transmitidas com precisão e transparência.

A GPR é enquadrada por seus autores, especificamente por Lancelot, na categoria das "obras de raciocínio", sendo considerada um "pequeno Tratado" (ARNAULD; LANCELOT, [1660] 1992, prefácio) sobre os usos do francês setecentista. Já no prefácio, os autores demarcam a preocupação com o "bom uso" da língua, encapsulado na palavra ${ }^{3}$. Entretanto, o que eles entendem por "bom uso" diz respeito não ao bel usage, mas ao conhecimento das razões que subjazem aos usos, a uma reflexão embasada numa ciência linguística interessada em elucidar, mediante o clima da época, como falar e escrever de modo a não menosprezar a perfeição que convém ao homem.

Um diferencial da GPR com relação às gramáticas a ela contemporâneas é que a reflexão acerca dos usos do francês, isto é, da língua vernácula, será predominante. As diferenças entre as línguas são tomadas como variações em torno de um mesmo tema, pois o que se busca é aquilo que é comum a todas as línguas, os "universais linguísticos", como chamaria Chomsky na década de 1960.

Na GPR, a palavra é a unidade linguística privilegiada para análise. No capítulo V da primeira parte, Arnauld e Lancelot fazem a oposição entre fala e escrita, embora ainda lhes falte a terminologia da fonética moderna, com exemplos em francês. É interessante constatar que a ideia de "bom uso" dos autores nesse desiderato não é atrelada exclusivamente às regras da escrita. Além disso, a diferença entre fala 
e escrita não é vista como problemática ou mesmo como erro, mas como um fator constitutivo da língua em uso: "[...] os que se queixam tanto de que se escreve diferentemente daquilo que se pronuncia não têm sempre muita razão e que aquilo que chamam abuso por vezes não é inútil" (ARNAULD; LANCELOT, [1660] 1992, p. 20). Em que pese ao fato de os autores afirmarem que muitas vezes a diferença entre fala e escrita resulte simplesmente da "[...] mera corrupção que se infiltrou nas línguas ${ }^{4}$.

Para os gramáticos de Port-Royal, as palavras se definem como sendo "[...] sons distintos e articulados, que os homens transformam em signos para significar seus pensamentos" (ARNAULD; LANCELOT, [1660] 1992, p. 28), sendo objeto do pensamento aquilo que se passa no espírito. Para discernir a forma ou a maneira do pensamento, é necessário empregar o julgamento. Os autores apontam para a existência de dois tipos de palavras: as que significam os objetos dos pensamentos (nomes, artigos, pronomes, princípios, preposições e advérbios) e as que significam a forma e o modo dos pensamentos (verbos, conjunções e interjeições).

Na segunda parte da GPR, a morfologia é tratada na perspectiva do discurso, à época visto como uso da língua. Na perspectiva dos autores, as palavras foram criadas para que os homens pudessem expressar seus pensamentos. Para que isto fosse feito adequadamente, seria necessário compreender os fundamentos da gramática, sendo, para tanto, indispensável conhecer o que se passa no espírito, de onde advém a diversidade das palavras que compõem o discurso.

Toda gramática comporta modos de significar. Nesse sentido, a gramática se propõe a elucidar, através de um conjunto de regras operacionais, definições cujo objetivo é nortear o bom uso da língua com base nos princípios racionais que a constitui. Para os gramáticos de Port-Royal, a arte de pensar passa pelo padrão normativo do bom uso da linguagem, o qual não é fixado pelo uso linguístico de escritores renomados do vernáculo francês. O que fornece ao usuário o parâmetro do "bom uso" é a construção de frases que se adéquem ao que se pretende ilustrar, como, por exemplo, o emprego das frases "Le roi aime la reine" e "La reine aime le roi" para mostrar o funcionamento dos casos nominativo e acusativo, respectivamente, em francês (ARNAULD; LANCELOT, [1660] 1992, p. 48). 
Percebe-se aqui, bem como no corpo da obra de maneira geral, uma forte influência do pensamento cartesiano, especificamente no que concerne à obra intitulada Regras para a direção do espírito, de Renée Descartes. Nesta obra, o filósofo defende que, para refletir sobre algo, é necessário afastar-se de conjecturas oriundas da experiência de outrem ou mesmo do próprio pesquisador, mas ater-se ao fenômeno tal como ele se manifesta, através da intuição e por meio das capacidades intelectuais do espírito (DESCARTES, s.d.).

Nesse momento da ciência linguística francófona, não se privilegia o uso linguístico da Corte, nem tampouco o do povo, mas da aristocracia, que aprendeu a língua francesa e fazia circular capital monetário e cultural. Para cumprir essa tarefa, a gramática latina não era adequada, pois suas categorias não se prestavam à descrição das chamadas línguas vulgares. A Gramática de Port-Royal, portanto, desempenhou um importante papel na especialização do conhecimento técnico sobre a linguagem.

\section{Considerações Finais}

A Gramática de Port-Royal não influenciou apenas a França setecentista, mas o Ocidente como um todo, ao propor uma reflexão racionalista sobre a linguagem em termos gerais e universais. Ela se opôs ao pensamento linguístico dominante vigente na Europa à época no que concerne ao que se entendia como o "bom uso" da linguagem, desvinculado de um viés meramente estilístico e afeito a um ideal de clareza e precisão das ideias.

Não obstante, no contexto brasileiro, como bem aponta Vieira (2018), curiosamente vingou até durante praticamente todo o século XX na tradição gramatical o apreço pelo "bom uso" da língua precisamente no viés do estilo, do preciosismo e do purismo, trazendo exemplos de renomados escritores da literatura nacional e descartando da discussão a influência do falante sobre os usos da língua.

Passadas quase duas décadas do século XXI, percebe-se uma mudança de direção nos compêndios brasileiros, que buscam empreender uma reflexão linguística mais sintonizada com a prática dos falantes. Para se chegar a este patamar, certamente foram negados muitos pressupostos do logicismo de Port-Royal, sem os quais, no entanto, não seria possível nenhum gesto de subversão atual. 


\section{Referências}

ARNAUlD, A.; LANCELOT, C. Gramática de Port-Royal. Trad.: Bruno Fregni Basseto e Henrique Graciano Murachco. São Paulo: Martins Fontes (Clássicos), [1660] 2002.

AUROUX, S. A Revolução Tecnológica da Gramatização. 2. ed. Trad.: Eni Puccinelli Orlandi. Campinas, SP: Ed. da UNICAMP, 2009. CIZESCKI, F. Entre Chomsky e Port-Royal: uma análise da leitura chomskyana. Work. pap. linguíst., Florianópolis, v. 9, n. 1, p. 121-131, jan./jun. 2008.

COLOMBAT, B.; FOURNIER, J.M.; PUECH, C. Como se coloca o problema da generalidade. In:

Uma História das Ideias

Linguísticas. Trad.: de Jacqueline Léon e Marli Quadros Leite. 1. ed. São Paulo: Contexto, 2017.

DESCARTES, R. Regras para a direção do espírito. Trad.: João Gama. Lisboa: Edições 70, s.d. Disponível em: http://www.revistaliteraria.com.br/DescartesRegras.pdf. Acesso em: 20 jul. 2018.

LAGORIO, C. El valor de lo simbólico en un nuevo clima de época. Anales de la educación común, Buenos Aires, Tercer siglo, año 3, número 6, Educación y lenguajes, jul. 2007.

MOLINA, J. A. Forma lógica e forma gramatical na Lógica e na Gramática de Port-Royal. Notae Philosophicae Scientiae Formalis, v. 3, n. 1-2, p. 70-81, 2014. Disponível em: http://gcfcf.com.br/pt/files/2017/05/6-NPSF-v.3-n.-1-2Molina1.pdf.

Acesso em: 16 jun. 2018.

SANTOS, T. S. C. Gramática de Port-Royal - século XVII, 1660. In: Artigo: da Tékhne Grammatiké aos dias de hoje. 108f. Dissertação (Mestrado em Letras) - Universidade Federal do Paraná, Curitiba. p. 44-49, 2014.

VIEIRA, F. E. A orientação lógico-filosófica nas Gramáticas do Português. In: A Gramática Tradicional: História Crítica. 1. ed. São Paulo: Parábola, 2018.

\section{Notas}

* Graduada Letras pela Universidade Federal de Campina Grande (UFCG) e mestre em Linguística pela Universidade Federal da Paraíba (UFPB). Atualmente, é aluna regular do curso de doutorado em Linguística pelo PROLING/UFPB. 
${ }^{1}$ Lancelot publicou, entre 1644 e 1660, Nouvelle Méthode para o latim, em 1644; o grego, em 1655; o italiano, em 1660 e o espanhol, também em 1660.

${ }^{2} \mathrm{Na}$ GPR, o sistema linguístico corresponde ao acervo de regras que regem o uso correto da língua, o sistema de linguagem que caracteriza a comunicação (CIZESCKI, 2008).

${ }^{3}$ No trato da palavra, os autores tomam a letra como sinônimo de fonema, conceito ainda não formulado à época. Para fazer menção ao som, também se utilizam genericamente dos termos "caractere" e "figura".

${ }^{4}$ Id. p. 21. 